\title{
Nevroprotektiv effekt av hypotermi
}

BAKGRUNN Nevroprotektiv effekt av hypotermi er vist i kasuistikker og dyrestudier. Terapeutisk hypotermi blir brukt for nevroproteksjon under visse typer kirurgi og etter alvorlige hendelser som truer hjernen. Hensikten med denne oversiktsartikkelen er å beskrive effekten av slik behandling hos voksne.

KUNNSKAPSGRUNNLAG Vi gikk igjennom alle treff i PubMed etter fem søk. Studier ble inkludert dersom de hadde hypotermiprotokoll og mål på nevroproteksjon. Listen over randomiserte studier ble komplettert etter gjennomgang av fem internasjonale oversiktsartikler. 103 av 678 studier oppfylte inklusjonskriteriene, hvorav 48 kliniske. Ti av de kliniske studiene var randomisert, med normoterm kontrollgruppe.

RESULTATER Flere randomiserte kliniske studier tyder på at det å unngå hypertermi gir samme nevroproteksjon som terapeutisk hypotermi etter hjertestans og traumatisk hjerneskade, men det er stor variasjon i prognostiske faktorer og inklusjonskriterier hos pasientpopulasjonene, slik som tid til måltemperatur. I to studier fant man ingen forskjell i kognitiv funksjon etter langvarig aortakirurgi under dyp hypotermi sammenliknet med kortvarige normoterme inngrep. Dyrestudier viser nevroprotektiv effekt av hypotermi, men dette er avhengig av grad av anoksisk skade samt nedkjølingshastighet.

FORTOLKNING Det er fortsatt usikkert hvordan man best kan implementere terapeutisk hypotermi som nevroproteksjon etter akutte hendelser som truer hjernen. Hypotermi brukt under aortakirurgi synes å gi adekvat nevroproteksjon for langvarige inngrep.

Den moderne bruken av terapeutisk hypotermi har sine røtter tilbake til tidlig på 1800tallet, da den franske kirurgen DominiqueJean Larrey erkjente at nedkjølt kroppsvev hadde økt toleranse for hypoksi (1). Klinisk bruk av hypotermi for nevroproteksjon ble likevel ikke vanlig før i siste halvdel av 1900-tallet, og den første rapporterte bruken av hypotermi etter hjertestans ble publisert $\mathrm{i}$ 1958 (2).

Bruk av terapeutisk hypotermi er i dag utbredt $\mathrm{i}$ behandling av overlevende hjertestanspasienter som forblir komatøse etter hjerte-lunge-redning (3), og metoden brukes også ved kirurgiske prosedyrer, som aortabuekirurgi (4). De siste årene har store randomiserte studier indikert at det å unngå hypertermi har samme nevroprotektive effekt som å indusere moderat $\left(30-34{ }^{\circ} \mathrm{C}\right)$ hypotermi etter hjertestans (5) og traumatisk hjerneskade (6).

Den nevroprotektive effekten av hypotermi er likevel vist i flere rapporterte tilfeller av aksidentell hypoterm hjertestans. Ved Universitetssykehuset Nord-Norge har man gjort vellykket gjenoppvarming av pasienter med kroppstemperatur fra $13,7^{\circ} \mathrm{C}$ (7) og etter opptil sju timer hypoterm hjertestans (8). Ulykken i Præstø Fjord i 2011 illustrerer den nevroprotektive effekten av hypotermi ytterligere - sju danske ungdommer ble gjenoppvarmet etter flere timer med hypoterm hjertestans. Alle overlevde, og seks kom fra ulykken uten alvorlig nevrologisk sekvele (9).

På denne bakgrunn vil vi gi en oversikt over bruken av hypotermi i forskjellige terapeutiske prosedyrer og diskutere den nevroprotektive effekten av slik behandling hos voksne. Terapeutisk hypotermi mot hypoksisk-iskemisk encefalopati hos neonatale er bedre dokumentert og vil ikke bli omtalt nærmere i denne artikkelen (10).

\section{Kunnskapsgrunnlag}

Elektroniske litteratursøk ble gjennomført 26.8. 2014 i PubMed-databasen. Vi gikk gjennom alle artikkeltreff for de følgende fem søkene: \#1 «Therapeutic hypothermia» AND neuroprotection, \#2 stroke AND hypothermia AND neuroprotection, \#3 «cardiac arrest» AND hypothermia AND neuroprotection, \#4 surgery AND hypothermia AND neuroprotection og \#5 «therapeutic targeted temperature management». Videre ble eventuelle kliniske randomiserte artikler som falt utenfor våre søk inkludert fra andre oversiktsartikler (11-15).

Totalt ble 678 publikasjoner funnet. Hovedkriteriet for å inkludere artikler var at de hadde en hypotermiprotokoll samt at det var gjort en måling av nevroprotektiv effekt. Alle kasuistikker, studier på barn og nyfødte, studier der hypotermi var indusert med medikamenter eller lokal injeksjon av kalde væsker samt dyrestudier uten normoterm kontrollgruppe ble ekskludert.

Hypotermi ble definert som temperaturer under $35^{\circ} \mathrm{C}$. Studier med protokoller som inkluderte lavere temperaturer ble inkludert. For å få oversikt over publiserte studier som møtte de overnevnte kriteriene, ble et vidt

\author{
Erik Sveberg Dietrichs \\ erik.sveberg.dietrichs@uit.no \\ Akuttmedisinsk og anestesiologisk \\ forskningsgruppe \\ Institutt for klinisk medisin \\ Universitetet i Troms $\varnothing$ - Norges arktiske \\ universitet \\ og \\ Forsknings- og utdanningsavdelingen \\ Stiftelsen Norsk Luftambulanse \\ Drøbak \\ og \\ Universitetssykehuset Nord-Norge \\ Espen Dietrichs \\ Nevrologisk avdeling \\ Oslo universitetssykehus \\ og \\ Det medisinske fakultet \\ Universitetet i Oslo
}

ㄴ.

Engelsk oversettelse på www.tidsskriftet.no

HOVEDBUDSKAP

Terapeutisk hypotermi brukes for å beskytte hjernen etter enkelte akutte hendelser som kan true den og under kirurgi

Det er fortsatt usikkert hvordan terapeutisk hypotermi best kan implementeres for å ha nevroprotektiv effekt etter hjertestans og traumatisk hjerneskade

Hypotermi gir mulighet til å utføre langvarig aortakirurgi uten større nevrologisk sekvele enn etter kortvarige inngrep på normoterm pasient 
Tabell 1 Oversikt over randomiserte, kliniske pasientstudier med normoterm kontrollgruppe, som unders økte den nevroprotektive effekten av hypotermi

\begin{tabular}{|c|c|c|c|c|c|}
\hline Førsteforfatter & Diagnose & Antall & $\begin{array}{l}\text { Tempera- } \\
\operatorname{tur}\left({ }^{\circ} \mathrm{C}\right)\end{array}$ & Mål på nevroproteksjon & Effekt av hypotermi \\
\hline Fakin (48) & Aortaklaffkirurgi & 60 & 32 & P300 auditory evoked potentials & Ingen forskjell \\
\hline De Georgia (53) & Hjerneinfarkt & 40 & 33 & Infarktstørrelse & Ingen forskjell \\
\hline Hemmen (54) & Hjerneinfarkt & 59 & 33 & Modified Rankin scale, mortalitet & Ingen forskjell \\
\hline Nielsen (5) & Hjertestans & 950 & 33 & $\begin{array}{l}\text { Mortalitet, Cerebral Performance } \\
\text { Categories-skala }\end{array}$ & Ingen forskjell \\
\hline Castrén (44) & Hjertestans & 200 & 34 & $\begin{array}{l}\text { Mortalitet, Cerebral Performance } \\
\text { Categories-skala }\end{array}$ & Ingen forskjell \\
\hline Bernard (45) & Hjertestans & 77 & 33 & Mortalitet, funksjonsnedsettelse & Positiv \\
\hline $\begin{array}{l}\text { Hypothermia after Cardiac } \\
\text { Arrest Study Group (24) }\end{array}$ & Hjertestans & 275 & $32-34$ & $\begin{array}{l}\text { Mortalitet, Cerebral Performance } \\
\text { Categories-skala }\end{array}$ & Positiv \\
\hline Laurent (30) & Hjertestans & 61 & 32 & $\begin{array}{l}\text { Mortalitet, Cerebral Performance } \\
\text { Categories-skala }\end{array}$ & Positiv \\
\hline Hachimi-Idrissi (22) & Hjertestans & 30 & 34 & Mortalitet & Ingen forskjell \\
\hline Maekawa (6) & Traumatisk hjerneskade & 300 & $32-34$ & Glasgow Coma Scale, mortalitet & Ingen forskjell \\
\hline
\end{tabular}

spekter av mål på nevrologisk skade og nevroproteksjon inkludert: nevronskade i hippocampus, inflammasjon i hjernevev, standardiserte nevrologiske tester, EEG, mortalitet, hjerneødem, infarktstørrelse, serummarkører på hjerneskade, morfometrisk analyse av hjernevev, auditivt fremkalt respons (auditory evoked potentials) samt utslipp av eksitatoriske transmittorsubstanser.

Studiene ble vurdert for inklusjon ut fra sammendraget. Dersom dette var mangelfullt eller manglet, ble fulltekstversjonen innhentet for å kunne vurdere om studien møtte inklusjonskriteriene. Totalt ble 103 studier inkludert, hvorav 48 var pasientstudier. De resterende var eksperimentelle studier på følgende spesies: rotte $(n=42)$, ørkenrotte $(n=4)$, gris $(n=3)$, mus $(n=3)$, kanin $(\mathrm{n}=2)$, bavian $(\mathrm{n}=1)$. Vi har valgt å legge spesiell vekt på de av de kliniske studiene som var randomisert $(n=10)$. Basert på disse gir vi en oversikt over hvordan hypotermi blir brukt som en nevroprotektiv intervensjon hos voksne og relaterer effekten av slik behandling til kunnskap hentet fra eksperimentelle studier der man direkte har studert cerebrale fysiologiske effekter av hypotermi.

\section{Pasientstudier}

Det var stor variasjon i problemstillingene som ble belyst i de 48 pasientstudiene som ble inkludert. Totalt var det 31 studier (5, 16-45) der man hadde sett på effekten av hypotermi etter hjertestans, åtte om hypotermi ved hjerte- eller aortakirurgi (4, 46-52), fire som omhandlet hjerneinfarkt
(53-56), to om subaraknoidalblødning (57, $58)$, to omhandlet hjernekirurgi $(59,60) \mathrm{og}$ én traumatisk hjerneskade (6).

Av disse pasientstudiene var det ti randomiserte $(5,6,22,24,30,44,45,48,53,54)$ med en normoterm kontrollgruppe (tab 1). Av disse fant man i tre positiv effekt av hypotermi $(24,30,45)$, mens det i de sju andre ikke var forskjell mellom pasienter behandlet med hypotermi og pasienter med normotermi $(5,6,22,44,48,53,54)$.

\section{Hjertestans}

Terapeutisk hypotermibehandling av komatøse hjertestanspasienter etter gjenoppliving var den klart vanligste problemstillingen i de 48 kliniske studiene som oppfylte inklusjonskriteriene. I 1990-årene ble hypotermi i økende grad testet som nevroprotektiv behandling (3). Dette foranlediget at det i 2002 ble publisert to randomiserte studier i New England Journal of Medicine. Disse viste positiv effekt av hypotermibehandling etter hjertestans, og henholdsvis 77 (45) og 275 (24) pasienter var inkludert. Disse studiene la grunnlaget for bruk av terapeutisk hypotermi i retningslinjene for behandling av hjertestanspasienter (61).

I 2013 kom det imidlertid en stor randomisert studie ( 950 pasienter) der man undersøkte effekten av å forhindre hypertermi kontra hypotermibehandling etter hjertestans (5). I denne studien var det ingen forskjell i nevroprotektiv effekt mellom den pasientgruppen som ble behandlet med moderat hypotermi $\left(33^{\circ} \mathrm{C}\right)$ og den som fikk forebyggende behandling mot hypertermi $\left(36^{\circ} \mathrm{C}\right)$. Den nevroprotektive effekten av moderat hypotermi etter hjertestans virker derfor usikker sammenliknet med det kun å forhindre hypertermi. Pasientene ble riktignok randomisert til en av de to behandlingsgruppene opptil fire timer etter at spontan sirkulasjon var reetablert. Derfor er det mulig at inklusjon av pasienter i nedkjølingsprotokollen så sent som etter fire timer kan gjøre det vanskelig å påvise en eventuell nevroprotektiv effekt av hypotermi i randomiserte studier (5).

\section{Hjerneinfarkt}

Alle de fire inkluderte kliniske studiene på behandling av hjerneinfarkt er små og prospektive. Hong og medarbeidere (55) fant at hypotermi hadde positiv effekt på grad av funksjonshemning (modified Rankin Scale) etter tre måneder, sammenliknet med en normoterm gruppe. Denne studien er riktignok ikke randomisert, men har pasientmateriale fra to sykehus, hvorav man ved det ene kjølte ned pasientene, mens man ved det andre holdt dem normoterme.

COOL AID-studien (53), der man også så på bruk av hypotermi i hjerneinfarktbehandling, var derimot randomisert. I denne studien var det ingen forskjell i infarktstørrelse på MR mellom gruppene, men pasientene ble selektert for behandling inntil 12 timer etter symptomdebut. Dessuten er pasientgrunnlaget lite (40 pasienter). Det er derfor vanskelig å trekke konklusjoner fra denne studien. 
I ICTuS-L-studien hadde man satt seks timer som grense for inklusjon i protokollen. Heller ikke i denne ble det funnet forskjeller mellom hypoterm og normoterm behandling av pasientene (54).

\section{Aortakirurgi}

I to studier med normoterm kontrollgruppe så man på bruk av dyp hypotermi (kjernetemperatur $<30^{\circ} \mathrm{C}$ ) under aortakirurgi $(46$, 51). I begge disse ble pasientene kjølt ned til under $20^{\circ} \mathrm{C}$. Man fant ingen forskjell i kognitiv funksjon mellom pasienter behandlet $i$ et langvarig inngrep under dyp hypotermi og pasienter som gjennomgikk kortere inngrep under normotermi.

I begge studier regner forfatterne dette som et positivt resultat med tanke på nevroproteksjon, da det viser at hypotermi trygt kan brukes under operasjoner der langvarig hjertestans er en nødvendig del av den operative prosedyren. Denne preventive bruken av dyp hypotermi mot nevrologisk skade skiller seg derfor fra bruk av moderat hypotermi som intervensjonsbehandling etter hjertestans eller hjerneinfarkt.

\section{Eksperimentelle dyrestudier}

De fleste av de eksperimentelle studiene omhandlet hjerneinfarkt - hele 37 av 42 inkluderte rottestudier (62-98) samt alle de åtte studiene (99-106) som var gjort på mus, ørkenrotte eller bavian. I andre studier så man på den protektive effekten av hypotermi etter ryggmargsskade, aortakirurgi eller subaraknoidalblødning (107-111). I alt 47 (62-64, 67-94, 98-104, 106-114) av de totalt 55 eksperimentelle dyrestudiene rapporterte at hypotermi hadde nevroprotektiv effekt.

Bare fire av de eksperimentelle dyrestudiene var gjort i hjertestansmodeller, to av disse var rottestudier $(112,113)$ og to grisestudier $(114,115)$. Tre av dem støttet hypotermibehandling av hjertestanspasienter (112-114). En av disse studiene indikerte viktigheten av rask nedkjøling etter reetablering av spontan sirkulasjon (113). I denne rottestudien falt den nevroprotektive effekten av hypotermi raskt. Nedkjøling var ikke effektivt etter fire timer, noe som viser at den protektive effekten av hypotermi er avhengig av grad og varighet av anoksisk skade før behandling. Den samme effekten ble også sett i dyrestudier der man brukte terapeutisk hypotermi etter hjerneinfarkt (66, $78,93,102,103,106)$.

\section{Fysiologiske mekanismer}

Nedsatt metabolisme i hjernen ved lav temperatur kan forklare at hypotermi beskytter hjernecellene mot iskemi. Det er vist eksperimentelt at hjernens glukoseomsetning reduseres med rundt $5 \%$ for hver grad tem- peraturen reduseres (116). Forutsatt en direkte sammenheng mellom metabolisme og beskyttelseseffekt, burde nedkjøling til for eksempel $33{ }^{\circ} \mathrm{C}$ gi $20 \%$ reduksjon i skadeomfang. Laboratorieforsøk har imidlertid vist at den nevroprotektive effekten kan være enda sterkere $(117,118)$.

Videre kan en nevroprotektiv effekt av hypotermi ses uten signifikant reduksjon $i$ metabolismen, noe som tyder på at andre faktorer også må ha stor betydning (33). Nedkjøling kan påvirke en rekke av de mekanismene som forårsaker iskemisk hjerneskade $(14,118)$. Akkumulering og frigjøring av eksitotoksiske aminosyrer som glutamat reduseres. Hypotermi kan påvirke glutamatreseptorene slik at skadelig kalsiuminfluks til cellene blir begrenset. Hypotermi kan hemme inflammatoriske responser ved iskemi, slik at danning av frie oksygenradikaler, reaktive nitrogenforbindelser, cytokiner og matriksmetalloproteaser og proinflammatoriske mediatorer blir effektivt redusert $(14,119)$.

Ved iskemisk hjerneskade kan hjerneceller enten gjennomgå nekrotisk celledød eller apoptose. Hypotermi kan hemme apoptose gjennom å påvirke både kaspaseavhengige og kaspaseuavhengige cellulære mekanismer. Dessuten finnes det egne kuldesjokkproteiner (cold shock proteins) som kan øke cellenes overlevelse ved å hemme apoptose under nedkjøling (118).

Blod-hjerne-barrieren kan også skades ved iskemiske lesjoner. Dette gir blant annet risiko for hjerneødem. Mild hypotermi beskytter både mot barriereskade og ødem. Nedkjølingen kan trolig også hemme aktivering av vannkanaler ved iskemi, gjennom redusert ekspresjon av akvaporin 4 (118). Svært viktig er det nok også at hypotermi reduserer den hyperperfusjonen som normalt opptrer etter iskemi (120). Hyperperfusjon kan forverre hjerneskade både gjennom ødemdanning og ved å forårsake risiko for blødninger i det skadede vevet.

\section{Diskusjon}

Den nevroprotektive effekten av nedkjøling virker klar ut fra eksperimentelle studier og erfaringer fra aksidentell hypotermi. Likevel er den kliniske dokumentasjonen fortsatt ikke tilstrekkelig til å kunne gjøre en kunnskapsbasert evaluering av terapeutisk hypotermi for noen av de områdene som er omtalt i denne artikkelen. Bruken av dyp hypotermi under aortakirurgi virker imidlertid godt begrunnet, da det gir mulighet for mer langvarige inngrep med sirkulasjonsstans.

Når det gjelder komatøse pasienter etter hjertestans, varierer både tiden til start av hjerte-lunge-redning og tiden til effektiv hypotermi mellom studiene. Derfor er det fortsatt ikke endelig dokumentert om mode- rat hypotermi har bedre effekt enn bare det å unngå hypertermi. Nye randomiserte studier der hypotermibehandling startes raskt etter hjertestansen, er nødvendig for å kunne avklare dette.

Ved hjerneinfarkt er det foreløpig lite som tilsier at vi skal begynne å bruke terapeutisk hypotermi. Ingen av de kontrollerte kliniske studiene har vist protektiv effekt av hypotermi, og nedkjøling øker komplikasjonsrisikoen for hjertearytmi og pneumoni. Dessuten har medikamentene som brukes for intravenøs trombolytisk behandling ved hjerneinfarkt, dårligere effekt ved lave temperaturer.

De varierende kontrollgruppebetingelsene gjør det vanskelig å sammenlikne den nevroprotektive effekten av terapeutisk hypotermi direkte forskjellige studier imellom. Til tross for at det er få randomiserte studier som viser slik effekt, er den nevroprotektive effekten av nedkjøling vist i flere rapporterte tilfeller av langvarig hjertestans etter aksidentell hypotermi uten betydelig nevrologisk sekvele (7-9). Dette tyder på god nevroprotektiv effekt av å senke kroppstemperaturen før hjertet stopper.

Hypoksisk normoterm hjertestans skiller seg fra hjertestans forbundet med aksidentell hypotermi ved at hjernens metabolske krav ikke er senket før hjertestans. Det er vist at rundt $40 \%$ av hjertestanspasienter som er blitt behandlet med hypotermi, utskrives fra sykehus uten alvorlig nevrologisk sekvele (121). Pneumoni er den vanligste komplikasjonen under slik behandling, sammen med arytmier, metabolske forstyrrelser og epileptiske anfall (122). Medikamentell behandling mot disse komplikasjonene av hypotermi kan derfor ha potensial til å øke overlevelsen i denne pasientgruppen, men er utfordrende på grunn av hypotermiinduserte endringer i medisinenes farmakologiske egenskaper $(123,124)$.

I pasientgrupper som behandles med hypotermi for å begrense hjerneskaden etter en iskemisk hendelse, synes det å være nødvendig å starte behandlingen så tidlig som mulig. Dermed får man best mulig nytte av de nevroprotektive mekanismene som er vist i eksperimentelle dyrestudier. Selektiv hjernekjøling i bavian til $25^{\circ} \mathrm{C}, 21 / 2$ time etter okklusjon av venstre a. carotis og a. cerebri anterior reduserte infarktstørrelsen til 0,5\% i venstre hemisfære, sammenliknet med $35 \%$ i normoterme dyr (99).

Slik rask nedkjøling er forskjellig fra det som skjer i randomiserte kliniske studier. I en studie ble pasientene inkludert opptil 12 timer etter symptomdebut (53). I Nielsen og medarbeideres store studie, der man så at det å unngå hypertermi hadde samme effekt som hypotermi, tok det også inntil 12 timer før måltemperaturen på $33^{\circ} \mathrm{C}$ ble nådd hos hypotermipasientene (5). Bernard og med- 
arbeidere, som viste nevroprotektiv effekt av hypotermi mot anoksisk hjerneskade, kjølte pasientene raskt til en kjernetemperatur på $33,5^{\circ} \mathrm{C}$ allerede to timer etter at spontan sirkulasjon var oppnådd (45). Rask nedkjøling synes altså å være svært viktig for å gi optimal nevroprotektiv effekt av terapeutisk hypotermi.

Videre fikk $73 \%$ av pasientene i Nielsen og medarbeideres studie hjerte-lunge-redning av publikum, noe som kan ha bidratt til en kortere anoksisk periode enn hos hypotermipasientene i studien til Bernard og medarbeidere, der bare $49 \%$ av fikk hjerte-lungeredning. Dermed er det mulig at pasientene i den sistnevnte studien var i større risiko for hjerneskade og dermed hadde større nytte av nevroprotektiv behandling enn pasientene i Nielsen og medarbeideres studie (5).

Den positive effekten av selektiv hjernekjøling hos bavian må også ses i lys av at de ble kjølt ned til $25^{\circ} \mathrm{C}$, mot normalt $32-34{ }^{\circ} \mathrm{C}$ i kliniske studier. Dette kan ha bidratt til å redusere infarktstørrelsen ved å redusere metabolismen ytterligere (116). En studie publisert etter at litteratursøket ble gjort kunne imidlertid ikke bekrefte at rask terapeutisk hypotermi etter hjertestans er effektivt (125). Resultatene fra denne studien er riktignok omdiskutert, med tanke på om hjerte-lunge-redning ble startet tidlig nok og om pasientene som ble inkludert dermed var for skadet til å kunne dra nytte av en eventuell nevroprotektiv effekt av hypotermi (126).

Det er fortsatt ikke avklart om hypotermibehandling bare forsinker celleskaden eller om den også kan ha mer langvarige effekter. Det skjer en rekke plastiske forandringer $\mathrm{i}$ hjernen etter iskemisk skade, inkludert nydanning av hjerneceller og omfattende synaptiske forandringer. I en studie der man så på postiskemisk tilheling og nydanning av hjerneceller i hippocampus, fant man flest nydannede nevroner hos de rottene som var behandlet med langvarig hypotermi (94). Enten kan redusert apoptose gjøre at flere nydannede nevroner overlever eller nevroneogenesen blir stimulert av hypotermi. Kanskje er begge mekanismene involvert.

Det ser også ut som om nydanningen av gliaceller øker etter hypotermibehandling, dessuten skjer det økt nydanning av blodårer (118). Hvorvidt dette siste er en fordel eller en ulempe, er usikkert. Likevel ser det ut som nedkjøling i sum har gunstige langtidsvirkninger på reparasjonsprosessen (118).

\section{Erik Sveberg Dietrichs If. 1985}

har en doktorgrad på hypotermi og er turnuslege.

Forfatter har fylt ut ICMJE-skjemaet og oppgir ingen interessekonflikter.

\section{Espen Dietrichs (f. 1956)}

er spesialist i nevrologi, avdelingssjef og professor.

Forfatter har fylt ut ICMJE-skjemaet og oppgir følgende interessekonflikter: Han har mottatt forelesningshonorar fra AbbVie, Allergan, GlaxoSmithKline, Medtronic og Nordic Infucare og rådgivningshonorar fra Britannia og Global Kinetics Corporation.

\section{Litteratur}

1. Remba SJ, Varon J, Rivera A et al. DominiqueJean Larrey: the effects of therapeutic hypothermia and the first ambulance. Resuscitation 2010 81: $268-71$.

2. Williams GR, Spencer FC. The clinical use of hypothermia following cardiac arrest. Ann Surg 1958; 148: 462-8.

3. Karnatovskaia LV, Wartenberg KE, Freeman WD. Therapeutic hypothermia for neuroprotection: history, mechanisms, risks, and clinical applications. Neurohospitalist 2014; 4: 153-63.

4. Khaladj N, Shrestha M, Meck S et al. Hypothermic circulatory arrest with selective antegrade cerebral perfusion in ascending aortic and aortic arch surgery: a risk factor analysis for adverse outcome in 501 patients. J Thorac Cardiovasc Surg 2008; 135: 908-14.

5. Nielsen N, Wetterslev J, Cronberg T et al. Targeted temperature management at $33^{\circ} \mathrm{C}$ versus $36^{\circ} \mathrm{C}$ after cardiac arrest. N Engl J Med 2013; 369: 2197-206

6. Maekawa T, Yamashita S, Nagao S et al. Prolonged mild therapeutic hypothermia versus fever control with tight hemodynamic monitoring and slow rewarming in patients with severe traumatic brain injury: a randomized controlled trial. J Neurotrauma 2015; 32: 422-9.

7. Gilbert M, Busund R, Skagseth A et al. Resuscitation from accidental hypothermia of 13.7 degrees C with circulatory arrest. Lancet 2000; 355: 375-6.

8. Mark E, Jacobsen O, Kjerstad A et al. Hypothermic cardiac arrest far away from the center providing rewarming with extracorporeal circulation. Int J Emerg Med 2012; 5: 7

9. Wanscher M, Agersnap L, Ravn J et al. Outcome of accidental hypothermia with or without circulatory arrest: experience from the Danish Præstø Fjord boating accident. Resuscitation 2012; 83: 1078-84.

10. Thoresen M. Who should we cool after perinatal asphyxia? Semin Fetal Neonatal Med 2015; 20: $66-71$.

11. Groysman LI, Emanuel BA, Kim-Tenser MA et al. Therapeutic hypothermia in acute ischemic stroke. Neurosurg Focus 2011; 30: E17.

12. Little NE, Feldman EL. Therapeutic hypothermia after cardiac arrest without return of consciousness: skating on thin ice. JAMA Neurol 2014; 71 $823-4$.

13. Gutsche JT, Ghadimi K, Patel PA et al. New frontiers in aortic therapy: focus on deep hypothermic circulatory arrest. J Cardiothorac Vasc Anesth 2014; 28: 1171-5.

14. Wu T-C, Grotta JC. Hypothermia for acute ischaemic stroke. Lancet Neurol 2013; 12: 275-84.

15. Sunde K, Søreide E. Therapeutic hypothermia after cardiac arrest: where are we now? Curr Opin Crit Care 2011; 17: 247-53.

16. Garrett JS, Studnek JR, Blackwell T et al. The association between intra-arrest therapeutic hypothermia and return of spontaneous circulation among individuals experiencing out of hospital cardiac arrest. Resuscitation 2011; 82: 21-5.

17. Aguila A, Funderburk M, Guler A et al. Clinical predictors of survival in patients treated with therapeutic hypothermia following cardiac arrest. Resuscitation 2010; 81: 1621-6

18. Batista LM. Lima FO, Januzzi JL Jr et al. Feasibi-
Lity and safety of combined percutaneous coronary intervention and therapeutic hypothermia following cardiac arrest. Resuscitation 2010. 81 : 398-403.

19. Bruel C, Parienti J-J, Marie W et al. Mild hypothermia during advanced life support: a preliminary study in out-of-hospital cardiac arrest. Crit Care 2008; 12: R31.

20. Buntaine AJ, Dangerfield C, Pulikottil T et al. Putting class $\mathrm{Ilb}$ recommendations to the test: the influence of unwitnessed and Non-VT/VF arrests on resource consumption and outcomes in therapeutic hypothermia and targeted temperature management. Crit Pathw Cardiol 2014; 13 $78-81$.

21. Grossestreuer AV, Abella BS, Leary M et al. Time to awakening and neurologic outcome in therapeutic hypothermia-treated cardiac arrest patients. Resuscitation 2013; 84: 1741-6.

22. Hachimi-Idrissi $\mathrm{S}$, Corne L, Ebinger $\mathrm{G}$ et al. Mild hypothermia induced by a helmet device: a clinical feasibility study. Resuscitation 2001; 51: 275-81.

23. Hinchey PR, Myers JB, Lewis R et al. Improved out-of-hospital cardiac arrest survival after the sequential implementation of 2005 AHA quidelines for compressions, ventilations, and induced hypothermia: the Wake County experience. Ann Emerg Med 2010; 56: 348-57.

24. Hypothermia after Cardiac Arrest Study Group. Mild therapeutic hypothermia to improve the neurologic outcome after cardiac arrest. N Engl J Med 2002; 346: 549-56

25. Ikeda K, Ikeda T, Taniuchi $\mathrm{H}$ et al. Comparison of whole-body cooling and selective head cooling on changes in urinary 8-hydroxy-2-deoxyguanosine levels in patients with global brain ischemia undergoing mild hypothermia therapy. Med Sci Monit 2012; 18: CR409-14

26. Kagawa E, Inoue I, Kawagoe T et al. Who benefits most from mild therapeutic hypothermia in coronary intervention era? A retrospective and propensity-matched study. Crit Care 2010; 14: R155.

27. Karnatovskaia LV, Festic E, Freeman WD et al. Effect of therapeutic hypothermia on gas exchange and respiratory mechanics: a retrospective cohort study. Ther Hypothermia Temp Manag 2014; 4: 88-95

28. Kim JJ Yang HJ Lim YS et al. Effectiveness of each target body temperature during therapeutic hypothermia after cardiac arrest. Am J Emerg Med 2011; 29: 148-54

29. Kulstad CE, Holt SC, Abrahamsen AA et al. Therapeutic hypothermia protocol in a community emergency department. West J Emerg Med 2010; 11: 367-72.

30. Laurent I, Adrie C, Vinsonneau C et al. Highvolume hemofiltration after out-of-hospital cardiac arrest: a randomized study. J Am Coll Cardiol 2005; 46: 432-7.

31. Leary M, Grossestreuer AV, lannacone $S$ et al. Pyrexia and neurologic outcomes after therapeu tic hypothermia for cardiac arrest. Resuscitation 2013; 84: 1056-61.

32. Lick C J, Aufderheide TP, Niskanen RA et al. Take Heart America: A comprehensive, communitywide, systems-based approach to the treatment of cardiac arrest. Crit Care Med 2011; 39: 26-33.

33. May TL, Seder DB, Fraser GL et al. Moderatedose sedation and analgesia during targeted temperature management after cardiac arrest. Neurocrit Care 2015; 22: 105-11.

34. Mooney MR, Unger BT, Boland $L L$ et al. Therapeutic hypothermia after out-of-hospital cardiac arrest: evaluation of a regional system to increase access to cooling. Circulation 2011; 124 $206-14$.

35. Okada $\mathrm{K}$, Ohde S, Otani $\mathrm{N}$ et al. Prediction protocol for neurological outcome for survivors of outof-hospital cardiac arrest treated with targeted temperature management. Resuscitation 2012; 83: $734-9$

36. Prior J, Lawhon-Triano M, Fedor D et al. Com munity-based application of mild therapeutic hypothermia for survivors of cardiac arrest. south Med J 2010; 103: 295-300. 
37. Storm C, Nee J, Krueger A et al. 2-year survival of patients undergoing mild hypothermia treatment after ventricular fibrillation cardiac arrest is significantly improved compared to historical controls. Scand J Trauma Resusc Emerg Med 2010; 18: 2 .

38. Stub D. Hengel C, Chan W et al. Usefulness of cooling and coronary catheterization to improve survival in out-of-hospital cardiac arrest. Am J Cardiol 2011; 107: 522-7.

39. Sunde K, Pytte M, Jacobsen D et al. Implementation of a standardised treatment protocol for post resuscitation care after out-of-hospital cardiac arrest. Resuscitation 2007; 73: 29-39.

40. van der Wal G, Brinkman S, Bisschops LLA et al. Influence of mild therapeutic hypothermia after cardiac arrest on hospital mortality. Crit Care Med 2011; 39: 84-8

41. Walters EL, Morawski K, Dorotta I et al. Implementation of a post-cardiac arrest care bundle including therapeutic hypothermia and hemodynamic optimization in comatose patients with return of spontaneous circulation after out-ofhospital cardiac arrest: a feasibility study. Shock 2011: 35: 360-6.

42. Nielsen N, Hovdenes J, Nilsson F et al. Outcome, timing and adverse events in therapeutic hypothermia after out-of-hospital cardiac arrest. Acta Anaesthesiol Scand 2009; 53: 926-34.

43. Leary M, Cinousis MJ, Mikkelsen ME et al. The association of body mass index with time to target temperature and outcomes following postarrest targeted temperature management. Resuscitation 2014: 85: 244-7.

44. Castrén M, Nordberg P, Svensson L et al. Intraarrest transnasal evaporative cooling: a randomized, prehospital, multicenter study (PRINCE: Pre-ROSC IntraNasal Cooling Effectiveness) Circulation 2010; 122: 729-36.

45. Bernard SA, Gray TW, Buist MD et al. Treatment of comatose survivors of out-of-hospital cardiac arrest with induced hypothermia. N Engl J Med 2002; 346: 557-63.

46. Chau KH, Friedman T, Tranquilli M et al. Deep hypothermic circulatory arrest effectively preserves neurocognitive function. Ann Thorac Surg 2013; 96: 1553-9

47. Ceriana P. Barzaghi N, Locatelli A et al. Aortic arch surgery: retrospective analysis of outcome and neuroprotective strategies. J Cardiovasc Surg (Torino) 1998; 39: 337-42.

48. Fakin R, Zimpfer D, Sodeck GH et al. Influence of temperature management on neurocognitive function in biological aortic valve replacement. A prospective randomized trial. J Cardiovasc Surg (Torino) 2012; 53: 107-12.

49. Kouchoukos NT, Masetti P, Murphy SF. Hypothermic cardiopulmonary bypass and circulatory arrest in the management of extensive thoracic and thoracoabdominal aortic aneurysms. Semin Thorac Cardiovasc Surg 2003; 15: 333-9.

50. Patel HJ, Nguyen C. Diener AC et al. Open arch reconstruction in the endovascular era: analysis of 721 patients over 17 years. J Thorac Cardiovasc Surg 2011; 141: 1417-23

51. Percy A, Widman S, Rizzo JA et al. Deep hypothermic circulatory arrest in patients with high cognitive needs: full preservation of cognitive abilities. Ann Thorac Surg 2009; 87: 117-23.

52. Nathan HJ, Munson J, Wells G et al. The management of temperature during cardiopulmonary bypass: effect on neuropsychological outcome. J Card Surg 1995; 10 (suppl): 481-7.

53. De Georgia MA, Krieger DW, Abou-Chebl A et al. Cooling for Acute Ischemic Brain Damage (COOL AID): a feasibility trial of endovascular cooling. Neurology 2004; 63: 312-7.

54. Hemmen TM, Raman R, Guluma KZ et al. Intravenous thrombolysis plus hypothermia for acute treatment of ischemic stroke (ICTuS-L): final results. Stroke 2010; 41: 2265-70.

55. Hong JM, Lee JS, Song H-J et al. Therapeutic hypothermia after recanalization in patients with acute ischemic stroke. Stroke 2014; 45: 134-40.

56. Krieger DW, De Georgia MA, Abou-Chebl A et al.
Cooling for acute ischemic brain damage /cool aid): an open pilot study of induced hypothermia in acute ischemic stroke. Stroke 2001: 32 1847-54.

57. Muroi C, Frei K, El Beltagy $M$ et al. Combined therapeutic hypothermia and barbiturate coma reduces interleukin- 6 in the cerebrospinal fluid after aneurysmal subarachnoid hemorrhage. J Neurosurg Anesthesiol 2008; 20: 193-8.

58. Karnatovskaia LV, Lee AS, Festic E et al. Effect of prolonged therapeutic hypothermia on intracranial pressure, organ function, and hospital outcomes among patients with aneurysmal subarachnoid hemorrhage. Neurocrit Care 2014; 21 451-61.

59. Mahaney KB, Todd MM, Bayman EO et al. Acute postoperative neurological deterioration associated with surgery for ruptured intracranial aneurysm: incidence, predictors, and outcomes. J Neurosurg 2012; 116: 1267-78.

60. Mack WJ, Ducruet AF, Angevine PD et al. Deep hypothermic circulatory arrest for complex cerebral aneurysms: lessons learned. Neurosurgery 2008; 62 (suppl 3): 1311-23

61. Peberdy MA, Callaway CW, Neumar RW et al. Part 9: post-cardiac arrest care: 2010 American Heart Association Guidelines for Cardiopulmonary Resuscitation and Emergency Cardiovascula Care. Circulation 2010; 122 (suppl 3): S768-86.

62. Schmid-Elsaesser R, Hungerhuber E, Zausinger $S$ et al. Combination drug therapy and mild hypo thermia: a promising treatment strategy for reversible, focal cerebral ischemia. Stroke 1999 30: $1891-9$.

63. Oh JS, Kim SW, Cho HJ et al. Combination treatment with $17 \beta$-estradiol and therapeutic hypothermia for transient global cerebral ischemia in rats. Am J Emerg Med 2013; 31: 154-60.

64. Tirapelli DPDC, Carlotti CG Jr, Leite JP et al. Expression of HSP70 in cerebral ischemia and neuroprotetive action of hypothermia and keto profen. Arq Neuropsiquiatr 2010; 68: 592-6.

65. Wang CX, Yang T, Noor R et al. Delayed minocycline but not delayed mild hypothermia protects against embolic stroke. BMC Neurol 2002; 2: 2 .

66. Dezena RA, Colli BO, Carlotti Junior CG et al. Pre, intra and post-ischemic hypothermic neuroprotection in temporary focal cerebral ischemia in rats: morphometric analysis. Arq Neuropsiquiatr 2012; 70: 609-16.

67. Zhao H, Shimohata T, Wang JQ et al. Akt contributes to neuroprotection by hypothermia against cerebral ischemia in rats. J Neurosci 2005; 25: 9794-806

68. Yanamoto H, Nagata I, Nakahara I et al. Combination of intraischemic and postischemic hypothermia provides potent and persistent neuroprotection against temporary focal ischemia in rats. Stroke 1999; 30: 2720-6, discussion 2726

69. Zhao H, Wang JQ, Shimohata T et al. Conditions of protection by hypothermia and effects on apop totic pathways in a rat model of permanent middle cerebral artery occlusion. J Neurosurg 2007; 107: 636-41

70. Berger C, Xia F, Köhrmann M et al. Hypothermia in acute stroke - slow versus fast rewarming. An experimental study in rats. Exp Neurol 2007. 204: $131-7$.

71. Ding $Y$, Li J, Luan $X$ et al. Local saline infusion into ischemic territory induces regional brain cooling and neuroprotection in rats with transien middle cerebral artery occlusion. Neurosurgery 2004; 54: 956-64.

72. Li J, Luan X, Lai $Q$ et al. Long-term neuroprotection induced by regional brain cooling with saline infusion into ischemic territory in rats: a behavioral analysis. Neurol Res 2004: 26: 677-83.

73. Ji X, Luo Y, Ling F et al. Mild hypothermia diminishes oxidative DNA damage and pro-death signaling events after cerebral ischemia: a mechanism for neuroprotection. Front Biosci 2007; 12: 1737-47.

74. Zausinger S, Westermaier T, Plesnila $\mathrm{N}$ et al. Neuroprotection in transient focal cerebral ischemia by combination drug therapy and mild hypothermia: comparison with customary therapeutic regimen. Stroke 2003; 34: 1526-32.

75. Horiguchi T, Shimizu K, Ogino M et al. Neuroprotection role of adenosine under hypothermia in the rat global ischemia involves inhibition of not dopamine release but delayed postischemic hypoperfusion. Brain Res 2002; 952: 222-31.

76. Westermaier T, Zausinger S, Baethmann A et al. No additional neuroprotection provided by barbi turate-induced burst suppression under mild hypothermic conditions in rats subjected to reversible focal ischemia. J Neurosurg 2000. 93: 835-44.

77. Ji Y, Hu Y, Wu Y et al. Therapeutic time window of hypothermia is broader than cerebral artery flushing in carotid saline infusion after transient focal ischemic stroke in rats. Neurol Res 2012 34: 657-63.

78. Ohta H, Terao Y, Shintani Y et al. Therapeutic time window of post-ischemic mild hypothermia and the gene expression associated with the neuroprotection in rat focal cerebral ischemia. Neurosci Res 2007; 57: 424-33

79. Lee S-H, Kim Y-H, Kim Y-J et al. Atorvastatin enhances hypothermia-induced neuroprotection after stroke. J Neurol Sci 2008; 275: 64-8.

80. Barone FC, Feuerstein GZ, White RF. Brain cooling during transient focal ischemia provides complete neuroprotection. Neurosci Biobehav Rev 1997: 21: 31-44.

81. Huh PW, Belayev L, Zhao W et al. Comparative neuroprotective efficacy of prolonged moderate intraischemic and postischemic hypothermia in focal cerebral ischemia. J Neurosurg 2000: 92: $91-9$

82. Wang F, Luo Y, Ling F et al. Comparison of neuro protective effects in ischemic rats with different hypothermia procedures. Neurol Res 2010; 32: 378-83

83. Maier CM, Sun GH, Kunis D et al. Delayed induction and long-term effects of mild hypothermia in a focal model of transient cerebral ischemia: neurological outcome and infarct size. J Neurosurg 2001: 94: 90-6.

84. Wei G, Hartings JA, Yang X et al. Extraluminal cooling of bilateral common carotid arteries as a method to achieve selective brain cooling for neuroprotection. J Neurotrauma 2008; 25 : 549-59.

85. Song W, Wu Y-M, Ji Z et al. Intra-carotid cold magnesium sulfate infusion induces selective cerebral hypothermia and neuroprotection in rats with transient middle cerebral artery occlusion. Neurol Sci 2013: 34: 479-86.

86. Inamasu J, Suga S, Sato S et al. Intra-ischemic hypothermia attenuates intercellular adhesion molecule-1 (ICAM-1) and migration of neutrophil. Neurol Res 2001: 23: 105-11.

87. Ceulemans A-G, Zgavc T, Kooijman R et al. Mild hypothermia causes differential, time-dependen changes in cytokine expression and gliosis following endothelin-1-induced transient focal cerebral ischemia. J Neuroinflammation 2011: 8. 60.

88. Zausinger S, Hungerhuber E, Baethmann A et al. Neurological impairment in rats after transient middle cerebral artery occlusion: a comparative study under various treatment paradigms. Brain Res 2000: 863: 94-105.

89. Maier CM, Ahern K, Cheng ML et al. Optima depth and duration of mild hypothermia in a foca model of transient cerebral ischemia: effects on neurologic outcome, infarct size, apoptosis, and inflammation Stroke 1998: 29: $2171-80$.

90. Corbett D, Hamilton M, Colbourne F. Persistent neuroprotection with prolonged postischemic hypothermia in adult rats subjected to transien middle cerebral artery occlusion. Exp Neurol 2000; 163: 200-6.

91. Colbourne F, Corbett D, Zhao Z et al. Prolonged but delayed postischemic hypothermia: a longterm outcome study in the rat middle cerebral artery occlusion model. J Cereb Blood Flow Metab 2000; 20: 1702-8.

92. Lagina AT, Deogracias M, Reed $K$ et al. The 
«Refrige-a-RAT-or»: an accurate, inexpensive, and clinically relevant small animal model of therapeutic hypothermia. Acad Emerg Med 2012: 19: 402-8.

93. Lee SM, Zhao H, Maier CM et al. The protective effect of early hypothermia on PTEN phosphorylation correlates with free radical inhibition in rat stroke. J Cereb Blood Flow Metab 2009; 29. 1589-600.

94. Silasi G, Colbourne F. Therapeutic hypothermia influences cell genesis and survival in the rat hippocampus following global ischemia. J Cereb Blood Flow Metab 2011: 31: 1725-35.

95. Lagina AT 3rd, Calo L, Deogracias M et al. Combination therapy with insulin-like growth factor-1 and hypothermia synergistically improves outcome after transient global brain ischemia in the rat. Acad Emerg Med 2013; 20: 344-51.

96. Theodorsson A, Holm L, Theodorsson E. Hypothermia-induced increase in galanin concentrations and ischemic neuroprotection in the rat brain. Neuropeptides 2008; 42: 79-87.

97. Ji Y-B, Wu Y-M, Ji Z et al. Interrupted intracarotid artery cold saline infusion as an alternative method for neuroprotection after ischemic stroke. Neurosurg Focus 2012; 33: E10.

98. Coimbra C, Drake M, Boris-Möller F et al. Longlasting neuroprotective effect of postischemic hypothermia and treatment with an anti-inflammatory/antipyretic drug. Evidence for chronic encephalopathic processes following ischemia. Stroke 1996; 27: 1578-85

99. Schwartz AE, Finck AD, Stone JG et al. Delayed selective cerebral hypothermia decreases infarct volume after reperfused stroke in baboons. J Neurosurg Anesthesiol 2011; 23: 124-30.

100. Cao Z, Balasubramanian A, Marrelli SP. Pharmacologically induced hypothermia via TRPV1 channel agonism provides neuroprotection following ischemic stroke when initiated 90 min after reperfusion. Am J Physiol Regul Integr Comp Physiol 2014; 306: R149-56

101. Li J, Benashski S, McCullough LD. Post-stroke hypothermia provides neuroprotection through inhibition of AMP-activated protein kinase. J Neurotrauma 2011; 28: 1281-8.

102. Kawabori M, Hokari M, Zheng Z et al. Triggering Receptor Expressed on Myeloid Cells-2 Correlates to Hypothermic Neuroprotection in Ischemic Stroke. Ther Hypothermia Temp Manag 2013; 3: 189-98.

103. Colbourne F, Corbett D. Delayed and prolonged post-ischemic hypothermia is neuroprotective in the gerbil. Brain Res 1994: 654: 265-72.

104. De Bow SB, Colbourne F. Delayed transient ischemic attacks kill some CA1 neurons previously salvaged with postischemic hypothermia: neuroprotection undone. Brain Res 2003; 959: $50-7$.

105. Corbett D, Larsen J, Langdon KD. Diazepam delays the death of hippocampal CA1 neurons following global ischemia. Exp Neurol 2008; 214 $309-14$

106. Corbett D, Nurse S, Colbourne F. Hypothermic neuroprotection. A global ischemia study using 18- to 20 -month-old gerbils. Stroke 1997; 28 2238-42, discussion 2243

107. Ha K-Y, Kim Y-H. Neuroprotective effect of moderate epidural hypothermia after spinal cord injury in rats. Spine 2008; 33: 2059-65.

108. OK J-H, Kim Y-H, Ha K-Y. Neuroprotective effects of hypothermia after spinal cord injury in rats: comparative study between epidural hypothermia and systemic hypothermia. Spine 2012; 37 E1551-9

109. Török E, Klopotowski M, Trabold R et al. Mild hypothermia (33 degrees C) reduces intracranial hypertension and improves functional outcome after subarachnoid hemorrhage in rats. Neurosurgery 2009; 65: 352-9, discussion 359

110. Wang LM, Yan Y, Zou LJ et al. Moderate hypothermia prevents neural cell apoptosis following spinal cord ischemia in rabbits. Cell Res 2005: 15: 387-93.

111. Maeda T, Mori K, Shiraishi Y et al. Selective occlusion of lumbar arteries as a spinal cord ischemia model in rabbits. Jpn J Physiol 2003; 53: 9-15.

112. Shin H-C, Tong S, Yamashita S et al. Quantitative EEG assessment of brain injury and hypothermic neuroprotection after cardiac arrest. Conf Proc IEEE Eng Med Biol Soc 2006; 1: 6229-32.

113. Che D, Li L, Kopil CM et al. Impact of therapeutic hypothermia onset and duration on survival, neurologic function, and neurodegeneration after cardiac arrest. Crit Care Med 2011; 39: 1423-30

114. Gong P. Hua R, Zhang Y et al. Hypothermia-induced neuroprotection is associated with reduced mitochondrial membrane permeability in a swine model of cardiac arrest. J Cereb Blood Flow Metab 2013; 33: 928-34.

115. Tang Z-X, Chen G-X, Liang M-Y et al. Selective antegrade cerebral perfusion attenuating the TLR4/NF-KB pathway during deep hypothermia circulatory arrest in a pig model. Cardiology 2014; 128: 243-50

116. Laptook AR, Corbett RJT, Sterett R et al. Quantitative relationship between brain temperature and energy utilization rate measured in vivo using $31 \mathrm{P}$ and $1 \mathrm{H}$ magnetic resonance spectroscopy. Pediatr Res 1995; 38: 919-25

117. Urrea C, Danton GH, Bramlett HM et al. The beneficial effect of mild hypothermia in a rat model of repeated thromboembolic insults. Acta Neuropathol 2004; 107: 413-20.

118. Yenari MA, Han HS. Neuroprotective mechanisms of hypothermia in brain ischaemia. Nat Rev Neurosci 2012: 13: 267-78.

119. Ceulemans A-G, Zgavc T, Kooijman R et al. The dual role of the neuroinflammatory response after ischemic stroke: modulatory effects of hypothermia. J Neuroinflammation 2010; 7: 74 .

120. Erecinska M, Thoresen M, Silver IA. Effects of hypothermia on energy metabolism in Mammalian central nervous system. J Cereb Blood Flow Metab 2003; 23: 513-30.

121. Dankiewicz J Schmidbauer S, Nielsen N et al. Safety, feasibility, and outcomes of induced hypothermia therapy following in-hospital cardiac arrest-evaluation of a large prospective registry. Crit Care Med 2014: 42: 2537-45.

122. Nielsen N, Sunde K, Hovdenes J et al. Adverse events and their relation to mortality in out-ofhospital cardiac arrest patients treated with therapeutic hypothermia. Crit Care Med 2011; 39: 57-64.

123. Tveita T. Pharmacodynamics in hypothermia. Update on therapeutic temperature management. Critical Care 2012; 6 (suppl 2): A6. http://ccforum. com/supplements/16/S2 (3.8.2015).

124. Pedersen TF, Thorbjørnsen ML, Klepstad P et al. Terapeutisk hypotermi - farmakologi og patofysiologi. Tidsskr Nor Lægeforen 2007; 127: 163-6.

125. Debaty G, Maignan M, Savary D et al. Impact of intra-arrest therapeutic hypothermia in outcomes of prehospital cardiac arrest: a randomized controlled trial. Intensive Care Med 2014; 40: $1832-42$

126. Cariou A, Sunde K. Cold fluids during cardiac arrest: faster cooling but not better outcome! Intensive Care Med 2014: 40: 1963-5.

Mottatt 17.10. 2014, første revisjon innsendt 31.3. 2015, godkjent 3.8. 2015. Redaktør: Trine B. Haugen. 